\title{
Incorporation of capric acid in pumpkin seed oil by $s n-1,3$ regioselective lipase-catalyzed acidolysis
}

\author{
Vanessa Sousa $^{1}$, Vitor Campos ${ }^{1}$, Patrícia Nunes ${ }^{1,2}$ and Paula Pires-Cabral ${ }^{1,2, *}$ \\ ${ }^{1}$ Instituto Superior de Engenharia, Universidade do Algarve, Campus da Penha, 8005-139 Faro, Portugal \\ 2 Center for Mediterranean Bioresources and Food (MeditBio), Universidade do Algarve, Campus de Gambelas, 8005-139 Faro, Portugal
}

Received 28 July 2017 - Accepted 21 December 2017

\begin{abstract}
Structured lipids (SLs) are novel triacylglycerols obtained by changing the native fatty acid (FA) profiles or by the incorporation of a new desired FA in the acylglycerol backbone. These modified fats present important medical and functional properties for food applications. This work aimed to synthetize a MLM-type SL, which consists of triacylglycerols containing a medium-chain FA (M) at $s n-1,3$ positions and a long-chain FA (L) at $s n-2$ position, by acidolysis of pumpkin seed oil with capric acid, catalyzed by a commercial lipase preparation from Thermomyces lanuginosa (Lipozyme TL IM). Reactions were performed at $45^{\circ} \mathrm{C}$, in solvent-free media, at 1:2 molar ratio (pumpkin seed oil:capric acid) and a fixed amount of immobilized lipase of $5 \%, 10 \%, 15 \%$ or $20 \%$. Incorporations of C10:0 increased with time up to $31 \mathrm{~h}(29.9 \pm 0.7 \mathrm{~mol}-\%)$ when 5\% lipase load was used. Significant differences were only observed between the results obtained with 5 and $20 \%$ of biocatalyst load. The subsequent experiment was carried out with $5 \%$ lipase load, at $45^{\circ} \mathrm{C}, 1: 2$ molar ratio and in the presence of $n$-hexane. The results showed slightly higher incorporation yields in the presence of solvent, namely at $48 \mathrm{~h}$-reaction $(34.7 \pm 1.0 \mathrm{~mol}-\%)$. However, since the structured lipids are to be used in food products, together with environmental and economic concerns, solvent-free systems are preferred. In this study, the synthesis of a MLM-type SL from pumpkin seed oil for food uses was well succeeded.
\end{abstract}

Keywords: structured lipid / acidolysis / pumpkin seed oil / capric acid / lipozyme TL IM

Résumé - Incorporation d'acide caprique dans de l'huile de pépin de citrouille par acidolyse catalysée par une lipase sn-1,3 régiosélective. Les lipides structurés sont de nouveaux triacylglycérols obtenus en changeant les profils des acides gras (AG) natifs ou par l'incorporation de nouveaux AG souhaités dans le squelette glycérol. Ces graisses modifiées présentent des propriétés médicales et fonctionnelles importantes pour des applications alimentaires. Ce travail vise à synthétiser un lipide structuré de type MLM, qui consiste en des triacylglycérols contenant un AG à chaîne moyenne (M) en positions sn-1,3 et un acide gras à chaîne longue (L) en position sn-2, par acidolyse de l'huile de graine de citrouille avec l'acide caprique, catalysée par une préparation commerciale de lipase de Thermomyces lanuginosa (Lipozyme TL IM). Les réactions ont été effectuées à $45^{\circ} \mathrm{C}$, sans solvant, avec un rapport molaire de 1:2 (huile de graines de citrouille: acide caprique) et une quantité fixe de lipase immobilisée de $5 \%, 10 \%, 15 \%$ ou $20 \%$. Avec une charge en lipase de $5 \%$, l'incorporation du C10:0 a augmenté avec le temps jusqu'à $31 \mathrm{~h}(29,9 \pm 0,7 \mathrm{~mol} \%)$. Des différences significatives ont été observées seulement entre les résultats obtenus avec 5 et $20 \%$ de charge en biocatalyseur. L'expérience suivante a été réalisée avec une charge en lipase de $5 \%$, à $45^{\circ} \mathrm{C}$, un rapport molaire $1: 2$ et en présence de n-hexane. Les résultats ont montré des rendements d'incorporation légèrement supérieurs en présence de solvant, à savoir $34,7 \pm 1,0 \mathrm{~mol} \%$ après $48 \mathrm{~h}$ de réaction. Cependant, étant donné que les lipides structurés doivent être utilisés dans les produits alimentaires, mais également pour des préoccupations environnementales et économiques, les systèmes sans solvant sont à privilégier. Dans cette étude, la synthèse d'un lipide structuré à visée alimentaire de type MLM à partir d'huile de graines de citrouille a été réalisée avec succès.

Mots clés : lipides structurés / acidolyse / huile de pépins de citrouille / acide caprique / lipozyme TL IM

\footnotetext{
*Corresponding author: pcabral@ualg.pt
} 


\section{Introduction}

During the last decades, the demand for new, healthy and economically viable products has increased considerably. Vegetable oils extracted from fruit seeds have an important functional and nutritional role in health due to their fatty acid (FA) composition and polyunsaturation level. Structured Lipids (SLs) can be produced by synthesis or modification of natural triacylglycerols (TAG). Constituent FAs of SL are medium chain FAs and unsaturated FAs (oleic, linoleic acid, polyunsaturated FA, etc.). In fact, they are novel TAG produced by the incorporation of new FAs, or changing the positions of FAs or the FA profile from the natural state $(\mathrm{Xu}$, 2000a, Ferreira-Dias et al., 2013). SLs are made to possess desired nutritional, physicochemical or textural properties for various applications in the food industry. Some interesting examples of SLs are human milk fat substitutes (Tecelão et al., 2010), cocoa butter substitutes (Matsuo et al., 1981), trans-free plastic fats for margarines (Osório et al., 2001) and low calorie fats and oils (Nunes et al., 2011a, b). The production of SL by enzymatic procedures has a great potential in the future market because of the specificity of lipases as biocatalysts (Kim and Akoh, 2015). TAG, containing a medium-chain FA (M) at $s n-1$ and $s n-3$ positions, and a long-chain FA (L) at $s n-2$ position, named as MLM-type TAG, present lower caloric value than conventional fats and oils of the type LLL (Smith et al., 1994; Morales-Medina et al., 2017). The importance of this SL is that it is metabolized differently compared to conventional fats and oils. In fact, this SL presents lower caloric value $(21-29 \mathrm{~kJ} / \mathrm{g}$ ) than conventional fats and oils $(38 \mathrm{~kJ} / \mathrm{g})$ due to the lower caloric content of $\mathrm{M}$ compared to their L counterparts (Smith et al., 1994). During digestion, $M$ is metabolized as rapidly as glucose. Since it is not readily re-esterified into new TAG, it has little tendency to accumulate in the body as stored fat, with weight control benefits (Osborn and Akoh, 2002). Therefore, it can be used for obesity reduction. Recently, Moreira et al. $(2017 \mathrm{a}, \mathrm{b})$ showed that SLs could play a major role in combating or preventing obesity and other resultant diseases without producing side effects. In addition, SLs may provide the most effective means of delivering desired FAs for nutritive or therapeutic purposes, and for treating specific diseases and metabolic problems (Osborn and Akoh, 2002, Lee et al., 2012). Lipases offer high catalytic efficiency, specificity, and selectivity by incorporation of the required acyl-group into a specific position of native TAG. In addition, the process takes place in very mild conditions that maintain unaltered the structure of the functional FA (Hita et al., 2007). Lipasecatalyzed acidolysis, in which medium chain FAs (caprylic, $\mathrm{C} 8: 0$, or capric acids, C10:0) are used as acyl donors, and vegetable or fish oils are used as the source of glycerol backbone and long chain FAs, is one of the most commonly used methods to produce SL of the MLM-type (Ferreira-Dias et al., 2013). The $s n-1,3$ specific lipases have currently been used to catalyze the incorporation of medium chain FAs at the $s n-1,3$ positions of the TAG molecule, while the central position is preferentially occupied by unsaturated long-chain FAs, namely oleic and linoleic acids (Osborn and Akoh, 2002; Turan et al., 2006; Feltes et al., 2009; Nunes et al., 2011a, b). Acidolysis reaction presents some advantages over other lipase-catalyzed reactions, such as esterification and inter- esterification. In fact, for MLM production via acidolysis, the acylglycerol mostly comes from native oils, which contain essential fatty acids, like linoleic acid, with health benefits. Currently, esterification gives the highest yield compared to acidolysis. However, large-scale esterification is more expensive than acidolysis due to the high cost of fatty acids and glycerol substrates. On the other hand, interesterification produces a randomly structured medium- long-chain tricylglycerols with low content of MLM compared to acidolysis reaction (Lee et al., 2012).

Pumpkin seed is a by-product of pumpkin fruit production and contains $45 \%$ oil average (dry weight basis), which is a major advantage over a number of other vegetable seed oils. Nowadays, this oil is used as a salad oil in several countries (Austria, Slovenia and Hungary), due to its pleasant sensory properties, high nutritive value and good oxidative stability, as it has a high content of natural antioxidants, such as phenolic compounds (Tsaknis et al., 1997; Murković et al., 2004; Yu et al., 2005; Stevenson et al., 2007; Fruhwirth and Hemetter, 2008; Vujasinovic et al., 2010). Moreover, this oil has gained attention, not only as an edible oil, but also as a potential nutraceutical. In fact, it is a good source of healthy compounds, especially phenolics, tocopherols (vitamin E) and carotenoids as lipophilic antioxidants (Stevenson et al., 2007), acting as preventative agents against hypertension and carcinogenic diseases (Zuhair et al., 2000; Jian et al., 2005). Also, the $\Delta 7$ sterols are specific to pumpkin seed oil and supposed to confer to this oil a beneficial effect in the treatment and prophylaxis of the prostate gland and bladder disorders (Nakić et al., 2006). In addition, it has an interesting FA composition, with four FAs making up $98 \%$ of the total, namely palmitic acid (C16:0, 9.5$14.5 \%)$, stearic acid (C18:0, 3.1-7.4\%), oleic acid (C18:1, 21.0-46.9\%) and linoleic acid (C18:2, 35.6-60.8\%) (Murković et al., 1996). Thus, pumpkin oil is extraordinarily rich in unsaturated FAs, which represent about $84 \%$ of the total FAs. Such health benefits mean that the effective extraction technologies are required to ensure the quality of pumpkin seed oil. Traditionally, pumpkin seed oil is obtained by pressing seeds previously roasted. However, a cold-press method using unroasted seeds is emerging because it produces oil with different and improved characteristics, namely sensory properties, such as colour, taste and odour, and FA profile (Nederal et al., 2012). In addition, this method of production preserves bioactive components, such as vitamins, provitamins, phytosterols, phospholipids and squalene, which are, together with some FAs, key pumpkin seed oil nutritional value factors (Rabrenović et al., 2014). In the literature, there is no reference regarding the enzymatic acidolysis of pumpkin seed oil with C10:0. Therefore, we have attempted to synthesize enzymatically MLM-type SLs from pumpkin seed oil for food uses. The aim of this study was:

- the extraction of oil from pumpkin (Cucurbita maxima, L.) seeds by cold-pressing and its characterization;

- the synthesis of a MLM-type SL, from this pumpkin seed oil enriched with $\mathrm{C} 10: 0$, catalyzed by a $s n-1,3$ regioselective commercial lipase prepared from Thermomyces lanuginosa (Lipozyme TL IM);

- to evaluate the effects of reaction parameters, namely, reaction time, substrates' molar ratio, and enzyme load on capric acid incorporation. 


\section{Materials and methods}

\subsection{Material and chemicals}

Pumpkin (Cucurbita maxima, L.) seeds were provided by Hortomelão Produtos Hortícolas e Frutos S.A., a local industry from the Santarém region, Portugal. Capric acid (C10:0, ndecanoic acid, melting point at $31^{\circ} \mathrm{C}$ ), and 2',7'-dichlorofluorescein were obtained from Fluka (Buchs, Switzerland). Fatty acid methyl ester (FAME) mix C8-C24 and FAME saturated and unsaturated standards, used for gas chromatography analysis, and lipid standard mono-, di- and triglyceride mix, used for thin layer chromatography analysis, were obtained from Sulpeco (Bellefonte, USA). Silica-Gel 60 $(0.25 \mathrm{~mm}$ width, $20 \times 20 \mathrm{~cm})$ thin layer chromatography plates were purchased from Merck (Darmstadt, Germany). All solvents and reagents for analyses were of chromatographic or analytical grade. The commercial immobilized $s n-1,3$ regioselective lipase, Lipozyme TL IM from Thermomyces lanuginosa, was a gift from Novozymes A/S (Bagsvaerd, Denmark).

\subsection{Seed preparation and oil extraction}

The provided frozen pumpkin seeds were thawed, washed with clean tap water and dried in a tray drier, where air at $45^{\circ} \mathrm{C}$ was forced by a fan to circulate over and parallel to the surface until a moisture content of 5\% (w:w) was achieved. The dried seeds were dehulled by hand and crushed in a hammer mill with a $0.75 \mathrm{~mm}$ sieve. The oil extraction was carried out using a screw press, Täby Press type 20 (Skeppsta Maskin AB, Sweden) equipped with an outlet nozzle of $9 \mathrm{~mm}$ internal diameter. The oil obtained was centrifuged during 15 minutes at $2500 \mathrm{rpm}$. Finally, the oil was stored at $-20^{\circ} \mathrm{C}$ in sealed tubes and protected from light until analysis. The oil extraction yield obtained by cold-pressing was expressed as the percentage of extracted oil by this method and the total oil content in the seeds, assessed by solvent extraction in a Soxhlet apparatus according to AOAC 948.22 method (2000), using $n$-hexane and a minimum extraction time of $8 \mathrm{~h}$.

\subsection{Physico-chemical characterisation and fatty acid composition of pumpkin seed oil}

Refractive index at $25^{\circ} \mathrm{C}$ (using a Abbe refractometer; Atago, 1T, Tokyo, Japan), specific gravity (using a $10 \mathrm{~mL}$ pycnometer at $19^{\circ} \mathrm{C}$ ), moisture content, acid value and peroxide value of the extracted pumpkin seed oil were determined by methods described by the AOAC (1984). Viscosity of the oil was measured using a viscometer (Brookfield, DV-II +; Middleboro, USA) equipped with a cylinder spindle. A thermostatic bath was used to control the working temperature at $21^{\circ} \mathrm{C}$. The speed of the rotating cylinder varied from $0.3 \mathrm{rpm}$ to $100 \mathrm{rpm}$. All analyses were performed in triplicate and average values \pm standard deviation were reported. FAME prepared by the method described by Nunes et al. (2011b) were dissolved in $100 \mu \mathrm{L}$ of $n$-hexane solution and $1 \mu \mathrm{L}$ of this solution was GC analyzed. A GC 14A gas chromatograph (Shimadzu; Kyoto, Japan) equipped with a flame ionization detector and a DB-wax capillary column
$(30 \mathrm{~m} \times 0.32 \mathrm{~mm}$ i.d., d.f. $=0.50 \mu \mathrm{m})$ was used. Injection and detector temperatures were set at $250^{\circ} \mathrm{C}$ and $260^{\circ} \mathrm{C}$, respectively. The injector was used in split mode with a ratio of 1:20. Helium was used as the carrier gas at a column head pressure of $10 \mathrm{kPa}$ and a flow rate of $1 \mathrm{~mL} / \mathrm{min}$. The oven temperature programme was as follows: $110^{\circ} \mathrm{C}$ for $7 \mathrm{~min}$, temperature increase to $170^{\circ} \mathrm{C}$ at $30^{\circ} \mathrm{C} / \mathrm{min}$, a plateau at $170^{\circ} \mathrm{C}$ for $45 \mathrm{~min}$, temperature increase to $230^{\circ} \mathrm{C}$ at $7.5^{\circ} \mathrm{C} / \mathrm{min}$ and a final plateau at $230^{\circ} \mathrm{C}$ for $15 \mathrm{~min}$. The relative content of FAME was calculated as a molar percentage on the basis of the molecular weight of each FAME.

\subsection{Acidolysis reaction}

A fixed amount of immobilized lipase, 5\% (w:w of total substrates) was added to the substrate mixture consisting of $3.0 \mathrm{~g}$ of pumpkin seed oil extracted by the cold-press method and $1.3 \mathrm{~g}$ of C10:0. The molar ratio of pumpkin seed oil:FA of $1: 2$ used corresponds to the stoichiometric value needed for the esterification of $\mathrm{C} 10: 0$ at the $s n-1$ and $s n-3$ positions, as the biocatalyst used was $s n-1,3$ selective. Lipozyme TL IM was used at its original water activity value, 0.201 (Nunes et al., $2011 b$ ). The reaction was carried out in solvent-free media, at $45^{\circ} \mathrm{C}$, in thermostatted-capped cylindrical glass vessels, under magnetic stirring at $250 \mathrm{rpm}$. In a time-course experiment, samples of $0.15 \mathrm{~mL}$ of reaction medium were withdrawn throughout $48 \mathrm{~h}$ and stored at $-20^{\circ} \mathrm{C}$ until analysis. In order to study the effect of lipase load in C10:0 incorporation, expressed in mol- $\%, 24 \mathrm{~h}$ acidolysis reactions were performed using different concentrations of biocatalyst $(5 \%, 10 \%, 15 \%$ and $20 \mathrm{w}$ : $\mathrm{w}$ of total substrates).

To select the best reaction media, namely solvent $v S$. solvent-free media, acidolysis reactions were carried out without solvent or in $n$-hexane media, at a ratio of total substrates:solvent of $1: 1.5(\mathrm{v}: \mathrm{v})$, at $45^{\circ} \mathrm{C}$, in thermostatedcapped cylindrical glass vessels under magnetic stirring at $250 \mathrm{rpm}$ for $48 \mathrm{~h}$ reaction-time. Acidolysis reactions were performed in triplicate and the average values \pm standard deviation were reported.

\subsection{Fatty acid incorporation assay}

This procedure was done according to the method described by Nunes et al. (2011b). Briefly, $0.1 \mathrm{~mL}$ of reaction medium was solubilized in $0.9 \mathrm{~mL}$ of chloroform and an aliquot of this product mixture $(200 \mu \mathrm{L})$ was separated by thinlayer chromatography (TLC) on silica gel plates and developed with $n$-hexane:ethyl ether:acetic acid (70:30:1.5, v:v:v). TLC plates were then air-dried and sprayed with $0.2 \%$ (w:v) 2',7'dichlorofluorescein in $95 \%$ ethanol and the bands were visualized under ultraviolet light at $366 \mathrm{~nm}$. The various groups of compounds (TAGs, free FAs, diacylglycerols and monoacylglycerols) were identified by comparison with standards. The TAG band was scraped from TLC plates and methylated and FAME were GC analyzed as previously described in the Section 2.3. The mol-\% incorporation of C10:0 into TAG was calculated according to Casas-Godoy et al. (2013) by the ratio of the moles of C10:0 in the TAG and the total moles of fatty acids in the triacylglycerols. 


\subsection{Statistical analysis}

To investigate the presence of eventual significant differences among biocatalyst loads, ANOVA of molar incorporation values was carried out using a Tukey's-b test. Differences were considered statistically significant at $p$ $<0.05$. All statistical analyses were performed using SPSS statistical software version 21.0 (IBM SPSS Statistics 21.0; Faro, Portugal).

\section{Results and discussion}

\subsection{Extraction yield}

The oil extraction yield obtained by cold-pressing pumpkin seeds from the Santarém region was $31.0 \%$. This value is similar to that reported by Jiao et al. (2014) with solvent extraction $(28.4 \%)$ and among the values obtained using hydrolytic enzymes $(29.4-59.9 \%)$ in a microwave-assisted aqueous enzymatic extraction of oil from pumpkin seeds. Also, Mitra et al. (2009) reported a maximum extraction yield of 30.7 wt.\% using supercritical carbon dioxide, nearly the same obtained in this study.

\subsection{Physico-chemical characteristics and fatty acid profile of pumpkin seed oil}

Due to the differences among the species and/or varieties of Cucurbita maxima grown in different areas of the world, physico-chemical characteristics of the extracted oil of pumpkin seeds from the Santarém region (Portugal) was undertaken before its use in the synthesis of a SL (Tab. 1). Refractive index and specific gravity values observed in the present work are in accordance with Codex Stan 210 (1999), which states a range from 1.447 to 1.477 and 0.881 to 0.929 , respectively for vegetable oils. Viscosity was lower than the data reported by Tsaknis et al. (1997) of $72 \pm 0.58 \mathrm{mPa} . \mathrm{s}$ for crude pumpkin seed oil from Cucurbita pepo and Cucurbita maxima. Moisture content and acid value were in accordance with Codex Stan 210 (1999), which points out maximum levels of $0.2 \%$ and $4 \mathrm{mg} \mathrm{KOH} / \mathrm{g}$ oil. The peroxide value obtained in this study $(19.008 \pm 1.710)$ was higher than the maximum limit of $15 \mathrm{meq} \mathrm{O}_{2} / \mathrm{kg}$ oil regulated by Codex Stan 210 (1999), which suggests that, at the moment of analysis, the pumpkin seed oil had begun to degrade by oxidation reactions, since the high amount of linoleic acid makes it specifically prone to oxidation. Three major FAs were identified: palmitic, oleic and linoleic (Tab. 1). Stearic acid was also present but in a considerably lower concentration. A high amount of total unsaturated FAs was observed $(75.9 \%)$, with linoleic acid being the FA with the highest expression (55.5\%). It is worth mentioning that linoleic acid possesses favourable nutritional and physiological effects in the prevention of coronary heart diseases and cancers (Oomah et al., 2000). Similar FA profiles of pumpkin seed oil were obtained by other authors (Murković et al., 2004; Popa et al., 2010; Kulkarni et al., 2012; Rezig et al., 2012; Procida et al., 2013; Jiao et al., 2014; Rabrenović et al., 2014), where their content and proportion, depended on the pumpkin varieties, climate and cultivation conditions.
Table 1. Physico-chemical properties and fatty acid profile of pumpkin seed oil from the Santarém region (Portugal).

\begin{tabular}{ll}
\hline Parameter & Mean $\pm \mathrm{SD}^{*}$ \\
\hline Refractive índex $\left(25^{\circ} \mathrm{C}\right)$ & $1.468 \pm 0.001$ \\
Specific gravity $\left(19^{\circ} \mathrm{C}\right)$ & 0.919 \\
Viscosity $\left(21^{\circ} \mathrm{C}, \mathrm{mPa} . \mathrm{s}\right)$ & $63.50 \pm 9.48$ \\
Moisture content $(\mathrm{w}: \mathrm{w}, \%)$ & $0.165 \pm 0.063$ \\
Acid value (mg KOH$/ \mathrm{g}$ oil) & $0.983 \pm 0.173$ \\
Peroxide value (meq $\mathrm{O}_{2} / \mathrm{kg}$ oil) & $19.008 \pm 1.710$ \\
\hline Fatty acid (mol-\%) & \\
\hline Palmitic $(\mathrm{C} 16: 0)$ & $\mathrm{Mean} \pm \mathrm{SD}^{*}$ \\
Stearic $(\mathrm{C} 18: 0)$ & $22.1 \pm 2.6$ \\
Oleic $(\mathrm{C} 18: 1)$ & $2.0 \pm 0.1$ \\
Linoleic $(\mathrm{C} 18: 2)$ & $20.4 \pm 0.8$ \\
\hline
\end{tabular}

${ }^{*}$ Mean of three replica \pm standard deviation

\subsection{Structured lipid synthesis}

Structured triacylglycerol was obtained by acidolysis of oil extracted from seeds of Cucurbita maxima pumpkin with C10:0, catalyzed by commercial lipase preparation from Thermomyces lanuginosa (Lipozyme TL IM). Reactions were carried out in a solvent-free media at $45^{\circ} \mathrm{C}$ with $5 \%$ (w:w) of immobilized lipase and a molar ratio of oil:C10:0 of 1:2. The effect of temperature on the incorporation of C10:0 into olive oil TAG in solvent free medium was previously studied by Nunes et al. (2011a, b). According to the authors, when the temperature was set at $45^{\circ} \mathrm{C}$, the viscosity of the reaction medium was reduced and the enzyme activity was such that a 28.8 mol-\% incorporation yield was achieved. Therefore, the acidolysis reaction of pumpkin seed oil with C10:0 was done at this temperature. The molar ratio substrates used $(1: 2)$ corresponds to the stoichiometric value needed for the esterification of $\mathrm{C} 10: 0$ at the $s n-1$ and $s n-3$ positions with this $s n-1,3$ selective enzyme. Despite sometimes a stoichiometric excess being advantageous in promoting FA incorporation, higher levels of substrate molar ratio could also positively affect acyl migration (Zou et al., 2015). Moreover, it is not economically justifiable to use a molar ratio of substrates higher than the stoichiometric value needed. In previous studies of enrichment of olive oil with medium chain FAs using biocatalysts with 1,3-regioselectivity and similar temperature and molar ratio conditions (Nunes et al., 2011b), sn-2 positional analysis were assayed and the $s n-2$ positions of the SLs obtained were predominantly occupied by oleic acid as in the original virgin olive oil. Therefore, in this study carried out under the same reactional conditions, FA composition at position-2 were not assayed. Monitoring the time course in enzymatic reactions is important in order to confirm the optimal reaction time for obtaining the highest yields and minimizing the overall costs in the processing. Time-course study (Fig. 1) indicated that the incorporation of C10:0 into pumpkin seed oil increased with time, reaching a plateau at $31 \mathrm{~h}(29.9 \pm 0.7 \mathrm{~mol}-\%)$. Although, incorporation values observed after $24 \mathrm{~h}$ were not significantly different. The same 


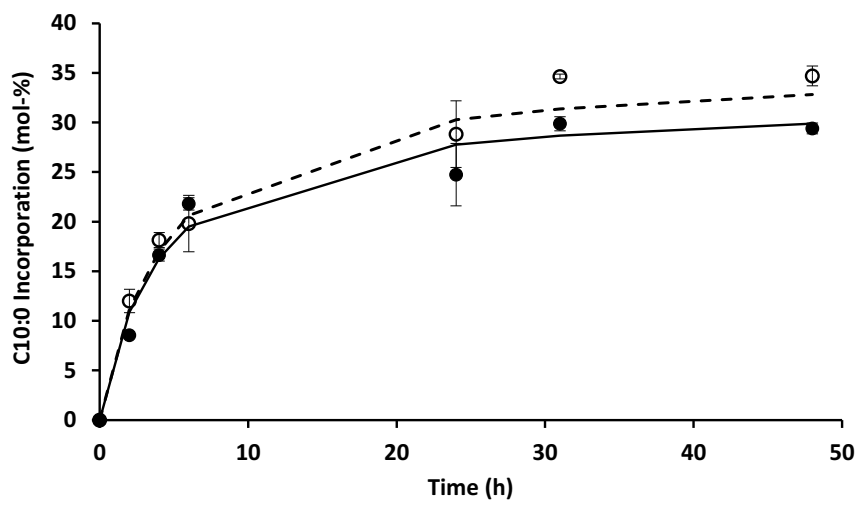

Fig. 1. Incorporations of C10:0 into pumpkin seed oil, catalyzed by $5 \%$ (w:w of total substrates) of Lipozyme TL IM in solvent free media (O) and in the presence of $n$-hexane (O).

Table 2. Effect of lipase load on C10:0 incorporation into pumpkin seed oil.

\begin{tabular}{ll}
\hline $\begin{array}{l}\text { Lipase load (w:w of total } \\
\text { substrates) }\end{array}$ & $\begin{array}{l}\text { C10:0 incorporation } \\
(\mathrm{mol}-\%)\end{array}$ \\
\hline 5 & $24.7 \pm 3.1^{\mathrm{a}}$ \\
10 & $27.4 \pm 2.7^{\mathrm{a}, \mathrm{b}}$ \\
15 & $27.5 \pm 2.4^{\mathrm{a}, \mathrm{b}}$ \\
20 & $29.6 \pm 1.9^{\mathrm{b}}$ \\
\hline
\end{tabular}

Each value of incorporation is the mean \pm standard deviation of 3 replica.

Different letters in the same column indicate significant differences according to Tukey's-b test $(p<0.05)$.

trend was observed when Lipozyme TL IM was used in the enrichment of olive oil with this medium chain FA, showing a maximum value of $28.8 \pm 3.0 \mathrm{~mol}-\%$ at $24 \mathrm{~h}$ reaction time (Nunes et al., 2011b). When higher lipase loads were tested $(10 \%, 15 \%$ and $20 \% \mathrm{w}: \mathrm{w}$ of total substrates), the incorporation values of C10:0 into pumpkin seed oil increased with the enzyme load, showing only significant differences when incorporation took place in the presence of $5 \%$ or $20 \%$, $24.7 \pm 3.1$ or $29.6 \pm 1.9$ mol- $\%$, respectively (Tab. 2 ). However, the incorporation increased only 1.2 times when lipase load increased from $5 \%$ to $20 \%$. According to Soumanou et al. (2013), higher enzyme amounts can accelerate the reaction rate and increase the incorporation during acidolysis, although high acyl migration may occur under these conditions. In fact, acyl migration depends on lipase load, enzyme supports with surface charges, water content and water activity, solvent and temperature (Iwasaki and Yamane, 2000; Xu 2000a, b, 2003; Fernadez-Lafuente, 2010). Also, de Araújo et al. (2016) reported that the increase of the lipase amount over the optimal value has no significant impact on the incorporation, probably due to the enzyme aggregation, which leads to an increase in substrate diffusion inhibition, causing the saturation of the reaction rate (Abed et al., 2017). Considering the marginal increase in the incorporation yield obtained with $20 \%$ lipase load, the subsequent study was carried out in the presence of
$5 \%$ of lipase to avoid acyl migration, as also reported by $\mathrm{Xu}$ et al. (1998). Moreover, higher lipase loads increase acidolysis process costs. The impact of the solvent on C10:0 incorporation into pumpkin seed oil by Lipozyme TL IM was investigated. In the presence of $n$-hexane, the incorporation of C10:0 into pumpkin seed oil increased with time up to 48 hours $(34.7 \pm 1.0 \mathrm{~mol}-\%)$ (Fig. 1). However, as observed in solvent free media, there are no significant differences between the incorporation yields after $24 \mathrm{~h}$ reaction time. The incorporation of C10:0 followed the same trend in both conditions, but slightly higher values were obtained in the presence of $n$-hexane, especially at 48 h-reaction, where the relative difference between solvent-free and hexane systems is about $18 \%$. Nevertheless, since the structured lipids are to be used in food products, together with environmental and economic concerns, solvent-free systems are preferred.

\section{Conclusions}

The physico-chemical characteristics of pumpkin seed oil and its FA profile suggest that it is a healthy oil mainly due to its rich composition in unsaturated FAs, especially oleic acid (20.4 mol-\%) and linoleic acid (55.5 mol-\%). The synthesis of a MLM-type SL by acidolysis of pumpkin seed oil with C10:0 catalyzed by Lipozyme TL IM was well succeeded. More precisely, $34.7 \mathrm{~mol}-\%$ of C10:0 incorporation was obtained in the presence of $n$-hexane, using a $5 \%$ enzyme load of Thermomyces lanuginosa lipase, 1:2 pumpkin oil:capric acid molar ratio, at $45^{\circ} \mathrm{C}$ and $48 \mathrm{~h}$ reaction time. The presence of high lipase loads did not considerably increase the incorporation yield of C10:0. Regarding the comparison between solvent-free and $n$-hexane systems, higher incorporations were observed in the presence of solvent. However, since the structured lipids are to be used in food products, solvent-free systems are preferred. Additional research on the quality of this SL can assist in efforts to achieve wide application in foods.

\section{References}

Abed SM, Zou X, Ali AH, Jin Q, Wang X. 2017. Synthesis of 1, 3-dioleoyl-2-arachidonoylglycerol-rich structured lipids by lipase-catalyzed acidolysis of microbial oil from Mortierella alpine. Bioresour Technol. Doi: 10.1016/j.biortech.2017.06.090.

AOAC. 1984. Official methods of analysis of AOAC International, 14th ed. Arlington: Association of Official Analytical Chemists International AOAC.

AOAC. 2000. Official methods of analysis of AOAC International, 17th ed. Arlington: Association of Official Analytical Chemists International AOAC.

Casas-Godoy L, Marty A, Sandoval G, Ferreira-Dias S. 2013. Optimization of medium chain length fatty acid incorporation into olive oil catalyzed by immobilized Lip2 from Yarrowia lipolytica. Biochem Eng J 77: 20-27. Doi: 10.10116/j.bej.2013.05.001.

Codex Stan 210. 1999. Codex standard for named vegetable oils. Codex Alimentarius, International Food Standards. Food and Agriculture Organization of the United Nations. World Health Organization. Available from http://www.fao.org/fao-who-codex alimentarius/sh-proxy/en/?lnk=1\&url=https $\% 253 \mathrm{~A} \% 252 \mathrm{~F} \%$ $252 \mathrm{Fw}$ orkspace.fao.org $\% 252 \mathrm{Fsites} \% 252 \mathrm{Fcodex} \% 252 \mathrm{FStan}$ $\mathrm{d}$ ard s \% 252 F C O D EX \% 2 B S TA N \% 2 B 210 - $1999 \%$ 252FCXS_210e.pdf. 
de Araújo MEMB, Campos PRB, Alberto TG, Contesini FJ, de Oliveira Carvalho P. 2016. Synthesis of structured triacylglycerols enriched in n-3 fatty acids by immobilized microbial lipase. Braz J Microbiol 47: 1006-1013. Doi: 10.1016/j.bjm.2016.07.003.

Feltes MMC, de Oliveira Pitol L, Gomes Correia JF, Grimaldi R, Block JM, Ninow JL. 2009. Incorporation of medium chain fatty acids into fish oil by chemical and enzymatic interesterification. Grasas Aceites 60: 168-176. Doi: 10.3989/gya.074708.

Fernadez-Lafuente R. 2010. Lipase from Thermomyces lanunginosa: Uses and prospects as an industrial biocatalyst. J Mol Catal B: Enzym 62(3-4): 197-212.

Ferreira-Dias S, Sandoval G, Plou F, Valero F. 2013. The potential use of lipases in the production of fatty acid derivatives for the food and nutraceutical industries. Electro $J$ Biotechnol. ISSN: 0717-3458. Doi: 10.2225/vol16-issue3-fulltext-5.

Fruhwirth GO, Hemetter A. 2008. Production technology and characteristics of Styrian pumpkin seed oil. Eur J Lipid Sci Technol 110: 637-644. Doi: 10.1002/ejlt.200700257.

Hita E, Robles A, Camacho B, et al. 2007. Production of structured triacylglycerols (STAG) rich in docosahexaenoic acid (DHA) in position 2 by acidolysis of tuna oil catalyzed by lipases. Proc Biochem 42: 415-422. Doi: 10.1016/j.bej.2009.05.015.

Iwasaki Y, Yamane T. 2000. Enzymatic synthesis of structured lipids. J Mol Catal B: Enzym 10(1-3): 129-140.

Jian L, Lee A, Binns C, Du C-J. 2005. Do dietary lycopene and other carotenoids protect against prostate cancer? Int J Cancer 113: 1010-1014. Doi: 10.1002/ijc.20667.

Jiao J, Li Z-G, Gai Q-Y, et al. 2014. Microwave-assisted aqueous enzymatic extraction of oil from pumpkin seeds and evaluation of its physicochemical properties, fatty acid compositions and antioxidant activities. Food Chem 147: 17-24. Doi: 10.1016/j. foodchem.2013.09.079.

Kim BH, Akoh CC. 2015. Recent research trends on the enzymatic synthesis of structured lipids. J Food Sci 80(8): 1713-1724. Doi: 10.1111/1750-3841.12953.

Kulkarni AS, More VI, Khotpal RR. 2012. Composition and lipid classes of orange, tomato and pumpkin seed oils of Vidarbha region of Maharashtra. $J$ Chem Pharm Res 4: 751-753. ISSN: 0975-7384, CODEN(USA): JCPRC5.

Lee Y-Y, Tang T-K, Lai O-M. 2012. Health benefits, enzymatic production, and application of medium- and long-chain triacylglycerol (MLCT) in food industries: a review. J Food Sci 77(8): 137-144. Doi: 10.1111/j.1750-3841.2012.02793.x.

Matsuo T, Sawamura N, Hashimoto Y, Hashida W. 1981. The enzyme and method for enzymatic transesterification of lipid. European Patent No. 0035883 (Fuji Oil Co.).

Mitra P, Ramaswamy HS, Chang KS. 2009. Pumpkin (Cucurbita maxima) seed oil extraction using supercritical carbon dioxide and physicochemical properties of the oil. J Food Eng 95: 208213. Doi: 10.1016/j.jfoodeng.2009.04.033.

Morales-Medina R, Munio M, Guadix A, Guadix EM. 2017. Development of an up-grading process to produce MLM structured lipids from sardine discards. Food Chem 228: 634642. Doi: 10.1016/j.foodchem.2017.02.019.

Moreira DKT, Santos PS, Gambero A, Macedo GA. 2017a. Evaluation of structured lipids with behenic acid in the prevention of obesity. Food Res Int 95: 52-58. Doi: 10.1016/j.foo dres.2017.03.005.

Moreira DKT, Ract JNR, Ribeiro APB, Macedo GA. 2017b. Production and characterization of structured lipids with antiobesity potential and as a source of essential fatty acids. Food Res Int 99: 713-719. Doi: 10.1016/j.foodres.2017.06.034.
Murković M, Hillebrand A, Winkler J, Leitner E, Pfannhauser W. 1996. Variability of fatty acid content in pumpkin seeds (Cucurbita pepo L.). Eur Food Res Technol 203: 216-219.

Murković M, Piironen V, Lampi AM, Kraushofer T, Sontag G. 2004. Changes in chemical composition of pumpkin seeds during the roasting process for production of pumpkin seed oil (Part 1: nonvolatile compounds). Food Chem 84: 359-365. Doi: 10.1016/ S0308-8146(03)00240-1.

Nakić SN, Rade D, Škevin D, Štrucelj D, Mokrovćak Ž, Bartolić A. 2006. Chemical characteristics of oils from naked and husk seeds of Curcubita pepo L. Eur J Lipid Sci Technol 108: 936-943. Doi: 10.1002/ejlt.200600161.

Nederal S, Škevin D, Kraljić K, Obranović M, Papeša S, Bataljaku A. 2012. Chemical composition and oxidative stability of roasted and cold pressed pumpkin seed oils. J Am Oil Chem Soc 89: 17631770. Doi: 10.1007/s11746-012-2076-0.

Nunes PA, Pires-Cabral P, Guillén M, Valero F, Ferreira-Dias S. 2011a. Production of MLM-type structured lipids catalyzed by immobilized heterologous Rhizopus oryzae lipase. J Am Oil Chem Soc 88: 473-480. Doi: 10.1007/s11746-010-1702-y.

Nunes PA, Pires-Cabral P, Ferreira-Dias S. 2011b. Production of olive oil enriched with medium chain fatty acids catalysed by commercial immobilised lipases. Food Chem 127: 993-998. Doi: 10.1016/j.foodchem.2011.01.071.

Oomah, BD, Ladet, S, Godfrey, DV, Liang, J, Girard, B. 2000. Characteristics of raspberry (Rubus idaeus L.) seed oil. Food Chem 69: 187-193. Doi: 10.1016/S0308-8146(99)00260-5.

Osborn HT, Akoh, CC. 2002. Structured lipids - novel fat with medical, nutraceutical and food applications. Compr Rev Food Sci F 1: 110-120. Doi: 10.1111/j.1541-4337.2002.tb00010.x.

Osório NM, Ferreira-Dias S, Gusmão JH, da Fonseca MMR 2001. Response surface modelling of the production of $\omega-3$ polyunsaturated fatty acids-enriched fats by a commercial immobilized lipase. J Mol Catal B: Enzym 11(4-6): 677-686. Doi: 10.1016/ S1381-1177(00)00156-9.

Popa V, Hădărugă NG, Hădărugă DL, et al. 2010. Fatty acids composition of some vegetable oils obtained in the west area of Romania. J Agroaliment Proc Technol 16: 394-398. Available from http://journal-of-agroalimentary.ro.

Procida G, Stancher B, Catenia F, Zacchigna M. 2013. Chemical composition and functional characterisation of commercial pumpkin seed oil. J Sci Food Agr 93: 1035-1041. Doi: 10.1002/jsfa.5843.

Rabrenović BB, Dimić EB, Novaković MM, Tešević VV, Basić ZN. 2014. The most important bioactive components of cold pressed oil from different pumpkin (Cucurbita pepo L.) seeds. LWT-Food Sci Technol 55(2): 521-527. Doi: 10.1016/j.lwt.2013.10.019.

Rezig L, Chouaibi M, Msaada K, Hamdi S. 2012. Chemical composition and profile characterisation of pumpkin (Cucurbita maxima) seed oil. Ind Crops Prod 37: 82-87. Doi: 10.1016/j. indcrop.2011.12.004.

Smith RE, Finley JW, Leveille GA. 1994. Overview of SALATRIM, a family of low-calorie fats. J Agr Food Chem 42: 432-434. Doi: 10.1021/jf00038a036.

Soumanou MM, Pérignon M, Villeneuve P. 2013. Lipase-catalyzed interesterification reactions for human milk fat substitutes production: A review. Eur J Lipid Sci Technol 115: 270-285. Doi: 10.1002/ejlt.201200084.

Stevenson DG, Eller FJ, Wang L, Jane J, Wang T. 2007. Oil and tocopherol content and composition of pumpkin seed oil in 12 cultivars. $J \mathrm{Agr}$ Food Chem 55: 4005-4013. Doi: 10.1021/jf0706979.

Tecelão C, Silva J, Dubreucq E, Ribeiro MH, Ferreira-Dias S. 2010. Production of human milk fat substitutes enriched in omega-3 
polyunsaturated fatty acids using immobilized commercial lipases and Candida parapsilosis lipase/acyltransferase. J Mol Catal B: Enzym 65(1-4): 122-127. Doi: 10.1016/j.molcatb.2010.01.026.

Tsaknis J, Lalas S, Lazos ES. 1997. Characterization of crude and purified pumpkin seed oil. Grasas Aceites 48: 267-272. Doi: 10.1016/j.foodchem.2010.02.018.

Turan S, Karabulut I, Vurak H. 2006. Effects of reaction parameters on the incorporation of caprylic acid into soybean oil for production of structured lipids. J Food Lipids 13: 306-317. Doi: 10.1111/j.1745-4522.2006.00054.x.

Vujasinovic V, Djilas S, Dimic E, Romanic R, Takaci A. 2010. Shelf life of cold-pressed pumpkin (Cucurbita pepo L.) seed oil obtained with a screw press. J Am Oil Chem Soc 87: 1497-1505. Doi: 10.1007/s11746-010-1630-x.

Xu X. 2000a. Production of specific structured triacylglycerols by lipase-catalyzed reactions: a review. Eur J Lipid Sci Tech 102: 287-303. Doi: 10.1002/(SICI)1438-9312(200004)102:4\% 3C287::AID-EJLT287\%3E3.3.CO;2-H.

Xu X. 2000b. Enzymatic production of structured lipids: Process reactions and acyl migration. Inform 11: 1121-1131.
Xu X. 2003. Engineering of enzymatic reactions and reactors for lipid modification and synthesis. Eur J Lip Sci Technol 105(6): 289304. Doi: 10.1002/ejlt.200390059.

Xu X, Balchen S, Høy C-E, Adler-Nissen J. 1998. Pilot batch production of specific-structured lipids by lipase-catalyzed interesterification: Preliminary study on incorporation and acyl migration. J Am Oil Chem Soc 75(2): 301-308. Doi: 10.1007/ s11746-998-0045-4.

Yu L, Parry JW, Zou K. 2005. Oils from herbs, spices and fruit seeds. In: Shahidi F, ed. Bailey's industrial oil and fat products. 6 th edn. USA: Wiley, vol. 3, pp. 250-252.

Zou X, Jin Q, Guo Z, Huang J, Xu X, Wang X. 2015. Preparation of 1, 3-dioleoyl-2-palmitoylglycerol-rich structured lipids from basa catfish oil: Combination of fractionation and enzymatic acidolysis. Eur J Lipid Sci Technol 118: 708-715. Doi: 10.1002/ ejlt.201500226.

Zuhair HA, Abd El-Fattah AA, El-Sayed MI. 2000. Pumpkin-seed oil modulates the effect of felodipine and captopril in spontaneously hypersensitive rats. Pharmacol Res 41: 555-563. Doi: 10.1006/ phrs.1999.0622.

Cite this article as: Sousa V, Campos V, Nunes P, Pires-Cabral P. 2018. Incorporation of capric acid in pumpkin seed oil by $s n-1,3$ regioselective lipase-catalyzed acidolysis. OCL 25(3): A302. 